\title{
Corrosion-Proof Steels
}

\section{Recent Progress in the Development of Iron Alloys That Resist Rust}

\author{
By F. Rowlinson
}

\begin{abstract}
W ITH the vast increase in the use of steel in constructional and engineering work, the problem of its
resistance to corrosion has reached a very considerable resistance to corrosion has reached a very considerable
degree of importance. Years ago, whenever permanence of structure was required, wrought iron was usually specified, because under proper conditions it has shown remarkable powers of resistance to certain forms of corrosion. Thus, for instance, there are in existence wrought iron columns at Delhi and chains at Adam's Peak, Ceylon, which have been proved to have been in their present state for thousands of years, notwithstandtheir present state for thousands of years, notwithstandacteristic of wrought iron seems to be due rather to a physical property resulting from the method of manufacture than to any chemical powers of resistance posiron results in a "fibrous" structure, really of attenuated crystals, each surrounded and insulated by a protective coating of $\mathrm{s}$. It is to this coating of slag. It is $t$ powers of resistance. But wrought iron is a costly or otherwise unsuitable material for most of the work for
which corrosion-proof steel is required, and the development of steel alloys has opened a vast door to the experimenter who seeks a corrosion-proof metal.
\end{abstract}

The materials now in use naturally divide themselves into two classes: Those where strength and a fair measure of resistance to corrosion are of importance, but where cost also has to be comparatively low. The second class includes those alloy steels in which the question of includes those alloy steels in which the question of
freedom from corrosion is of primary importance, and that of cost negligible in ccmparison.

\section{Nickel Steels}

All steels used in building and constructional work would, of course, be better if they could be made of corrosion-proof materials. The large quantities of steel used in modern construction have raised serious doubts as to the permanency of these structures. So that, wherever long life is desirable under more than ordinarily corrosive conditions, alloy steels are now in fairly common use. The first of these to attract notice was nickel mon use. The first of these to attract notice was nickel
steel. It was found that the presence of nickel in steel, while raising the mechanical properties of steel to a very valuable extent, conferred also upon it an increased resistance to corrosion. Figures by Prof. Howe have shown that, taking the corrosion of wrought iron as a sea water, fresh water and general atmospheric conditions was as follows:

Wrought Iron.

Mild Steel.

3 per cent Nickel Steel

26 per cent Nickel Steel. 31

The three per cent nickel steel proved more resistant to atmospheric corrosion than to that of sea or fresh water. So that the use of this material is growing where increased strength and resistance to corrosion outweigh its higher cost. The 26 per cent nickel steel is, of course, ruled out of court for all ordinary purposes, but for use in cases where the weight of metal is small in comparison with its importance, it has proved of grtat value. Instances of its use occur in scientific instruments, measuring tapes, and in non-corrodible fittings for automobiles, etc. Still higher percentages of nickel are often introduced; for instance, a 30 per cent nickel steel has proved in practice to give a life to marine boiler-tubes three times practice to give a life to marine boiler-tubes three times
that of plain steel. Nickel steel of this content may be drawn out into wire just as easily as plain steel; wire of this class has been prominent during the war as torpedo protection and in connection with various anti-submarine devices where its high tensile strength and toughness, it of the utmost value. Invar, an alloy of steel with 36 per cent of nickel, is exceedingly non-corrodible, and this coupled with the property of an extremely low this coupled with the property of an extremely low use in scientific apparatus.

\section{Copper Steels}

For many years the presence of copper in steels was looked upon with high disfavor by almost all steelmaker and users. Investigations by Howe, Colly, Müller, and Stead, to name but a few, have repeatedly demonstrated the fallacy of these beliefs, but until very recent years their conclusions have been ignored. Recently, however, opinion has somewhat changed, and now there are several firms who make a specialty of copper steel sheets containing from one tc three tenths of one per cent of copper. Comparative tests show that these sheets are more without further resistant to corrosion than the corresponding plain steels. Where copper is added to steel, the effect seems to be to increase the tensile strength without seriously affecting the elongation and contraction of area. But when the addition exceeds 0.75 per cent segregation of the copper sets in, with disastrous results. Up to that point the copper goes into solid solution with the free ironabove that point copper segregations are found.

\section{Nickel-Copper Steels}

Since it was found that both nickel and copper gave immunity from corrosion when added to steel, it was expected that a steel containing both would also be comparatively free from corrosion. This was found to be the case. But an additional feature was found to be present in the more complex steel so made. Providing the proportion of nickel to copper was never less than five to two, the copper does not segregate as it tends to do in carbon steel. In this way the copper content, and, therefore, the powers of resistance to corrosion may be very considerably increased. Moreover, as regards mechanical tests, the copper seems to replace perfectly an equal percentage of nickel, so that a nickel-copper steel with, say $21 / 2$ per cent nickel and 1 per cent copper steel with, say $21 / 2$ per cent nickel and 1 per cent copper
has the mechanical properties of a $31 / 2$ per cent nickel steel, with increased immunity from corrosion.

This variety of alloy steel has aroused considerable interest in Canada, where the nickel-bearing ores consist chiefly of iron sulphide with smaller quantities of nicke and copper sulphides, associated with a considerable quantity of siliceous gangue. During the refining process used in the extraction of the nickel and copper, large quantities of waste slag are produced, consisting large quantities of waste slag are produced, consisting
of iron silicate, with smaller quantities of nickel and of iron silicate, with smaller quantities of nickel and
copper retained from the ores. It is proposed to manufacture a nickel-copper steel from this slag by reduction in a blast furnace and subsequent refining in electric refining furnaces. A consideration of the electrochemical properties of nickel, copper, and iron indicates that no nickel or copper would be lost in the process, and the copper and nickel now wasted would be recovered

The properties of the steel are such as to render its future use in structural, and particularly in marine work, of vast possibility. The new steel is stated to resist sea water 20 times longer than plain steel, and to be even more resistant to the action of dilute acids. It seems probable that, as soon as the prejudice which as ye nickel-copper steel will come very much to the fore. It can be produced at a cost not much above that of a carbon steel, and certainly below that of the corresponding nickel steel in which the nickel has been added artificially to the molten bath.

\section{Chromium "Stainless" Steels}

While conducting experiments in search of a nonerodible steel for use in the lining of guns, Mr. H. Brearley, the eminent British metallurgist, discovered that a steel containing from 12 to 14 per cent of chromium was possed of quite remarkable properties as regards its immediately took up this new material, and from it was made the "stainless" cutlery which achieved popularity even prior to the war. This remarkable alloy steel, while not inferior in mechanical properties to plain carwhile not inferior in mechanical properties to plain car-
bon steel, possesses not only non-corrodibility under the action of weather, and of fruit juices and other dilute acids, but it is in a high degree resistant to wear by erosion and scaling at high temperatures. The new chromium steel is said to resist corrosive influences, even better than the 26 per cent nickel steel described above; in addition it may easily be softened for machine purposes, and afterward hardened. The high nickel steel is difficult to machine, even when soft, and will not take a high degree of hardness, at all events by such processes as are applicable to finished articles. The immunity of chromium steel to erosion is exceedingly marked, more particularly at high temperatures, and it is now in us with complete success for exhaust valves for internal combustion engines, and for turbine blades. Its adoption may possibly do much to aid the development of the internal combusion turbine-a machine of future possibilities, but which hitherto has met with more difficulties than success. Cutlery of all kinds may be made of socalled "stainless" steel; the benefit this application alone will confer upon the busy housewife is incalculable. A
most stringent test may be applied to this steel-that of allowing a few drops of commercial vinegar to evaporat at ordinary temperatures upon the blade. The absence of even the faintest mark is a very definite indication of its stainless properties. During the war the manufacture of "stainless" cutlery has been severely curtailed, since the greater part of the output of this steel was used in the manufacture of special parts for aircraft. But now we may expect to see the "stainless" cutlery again on the market. The application of this chrcmium steel to general engineering purposes is spreading rapidly to every problem where the greatly prolonged life offsets the problem where the greatly prolonged life offsets the
increased cost. Machine and engine parts such as pump increased cost. Machine and engine parts such as pump
rods, hot punches, acid pumps for chemical plant, water meters, roller bearings, etc., are now made with conspicuous success of this chromium steel. It is noteworthy that while the manufacture of this steel is patent-free as regards Great Britain, the inventor has taken out patent rights in almost every trading country. The United States patent rights are vested in a syndicate which is not a manufacturing company, but which exists for the granting of licenses and for the advising of licensees. It is also worthy of note that the syndicate proposes to establish a mark, and to accept a fair measure of responsibility for goods sold under that mark even though they be made under license.

A note as to the importance of the physical and mechanical conditions necessary to insure immunity from corrosion may not be out of place here. Although, of course, the chemical composition of a steel has the farthest reaching influence upon its powers of resistance to corrosion, it must be remembered that steels which under optimum conditions are practically non-corridible, may under unfavorable conditions yield results very little superior to plain steels. It is well known that steel may be "strain-hardened," and this pseudo-hardness or springiness is often given to steel articles by a process of forging or rolling at low temperatures. Such steel is quite unreliable as regards its powers of resistance, and in the case of many special steels such treatment will vitiate any desirable results of chemical composition. Where this cold working has been carried to an excessive degree, so that the internal structure of the steel has broken down, and the formaticn of "slip-bands" and amorphous intercrystalline layers has commenced, corrosion takes place readily. For instance drillings or turnings of any variety of corrosion-proof steel will rust rapidly, and surfaces which have been machined at high speed with the deep cuts used on modern machines are also subject to corrosion. It, may, therefore, be taken as axiomatic that any steel article required to show immunity from rust or corrosion should preferably not be worked in the cold state, or should have a final heattreatment (either annealing or hardening, according to the class of steel and the service required of it) calculated to remove internal and surface strains. Where heat treatment is not possible after machining, it is imperative that the finishing cuts should be as light as possible, that grinding should follow the rough machining, and that polishing should be the final process. It is well recognized that the crystalline structure of a metal is far less profoundly modified by grinding than by cutting, and that polishing differs radically from either process. Grinding, even if the particles of the abrasive are extremely small, must of necessity produce a multitude of minute parallel channels in the material, each channel surrounded by a strained and distorted structure due to the forcible removal of multitudinous small portions of metal. Polishing, on the other hand, actually fills up these abrasions by inducing a flow in the solid metal precisely as if it were a very viscous liquid. This phenomenon is well known to micrometallurgists, who frequently find that the polished surfaces of their specimens, apparently free from grinding scratches, are badly marked when the "flowed" layer has been removed by some etching reagent. Hence, a ground and polished surface is advisable where greatest resistance to corrosion is
sought after. The freedom of such a surface from mechanical starting-places for the commencement of corrosion also confers upon them some immunity.

Freedom from erosion and scaling, on the other hand, seem more dependent upon the chemical properties of the steel. Erosion would s eem to be a joint function of scaling and hardness at high temperatures. It is of course impossible that a surface undergoing erosion should be free from crystalline distortion, or that the surface of a metal at scaling temperature should be "clean." Nickel steels of 26 per cent nickel content, tungsten and high speed steels, and high chromium steels seem to be most resistant to scaling, and the latter to erosion at high temperatures. 